\title{
Érudition et culture savante de l'Antiquité à l'époque moderne, F. Brizay et V. Sarrazin (éds.)
}

\section{Maurizio Busca}

\section{(2) OpenEdition}

\section{Journals}

\section{Edizione digitale}

URL: http://journals.openedition.org/studifrancesi/9906

DOI: $10.4000 /$ studifrancesi.9906

ISSN: 2421-5856

\section{Editore}

Rosenberg \& Sellier

\section{Edizione cartacea}

Data di pubblicazione: 1 août 2017

Paginazione: 343

ISSN: 0039-2944

\section{Notizia bibliografica digitale}

Maurizio Busca, «Érudition et culture savante de l'Antiquité à l'époque moderne, F. Brizay et V. Sarrazin (éds.)», Studi Francesi [Online], 182 (LXI | II) | 2017, online dal 01 août 2017, consultato il 09 janvier 2021. URL: http://journals.openedition.org/studifrancesi/9906 ; DOI: https://doi.org/10.4000/ studifrancesi.9906

Questo documento è stato generato automaticamente il 9 janvier 2021.

\section{(c) $(1)$}

Studi Francesi è distribuita con Licenza Creative Commons Attribuzione - Non commerciale - Non opere derivate 4.0 Internazionale. 


\title{
Érudition et culture savante de l'Antiquité à l'époque moderne, $\mathrm{F}$. Brizay et V. Sarrazin (éds.)
}

\author{
Maurizio Busca
}

\section{NOTIZIA}

Érudition et culture savante de l'Antiquité à l'époque moderne, sous la direction de François BRIZAY et Véronique SARRAZIN, Rennes, Presses Universitaires de Rennes, 2015, «Histoire», $270 \mathrm{pp}$.

1 Il volume riunisce le comunicazioni tenutesi ad Angers durante la giornata di studi del 16 marzo 2012 e il seminario «Histoire comparée des cultures et des sociétés européennes» (2011-2012), dedicate al tema dell'erudizione dalla tarda antichità all'epoca moderna, in Europa e nel Vicino Oriente cristiano. Sono definite due grandi prospettive di ricerca. La prima guarda al rapporto dei savants con le loro fonti, antiche e moderne, e quindi al lavoro di studio, commento e trasmissione di testi che va ben al di là dei limiti della semplice compilazione - un esercizio di cui alcuni autori presi in esame, come Raban Maur, sono stati tacciati a lungo. La seconda concerne invece l'organizzazione e la circolazione dei saperi, e dunque il lavoro degli scriptoria e degli ateliers librari, gli scambi privati fra letterati, e l'attività culturale promossa da accademie, circoli e cabinets de lecture. I contributi raccolti sono i seguenti.

Première partie («Les sources de l'érudition»): Edith PARMENTIER, L'énigmatique "Anthologie" de Stobée. Organisation du recueil et fiabilité des textes transmis, pp. 19-35; Estelle BERTRAND, Ethnonymes, toponymes dans l'"Histoire romaine" de Cassius Dion: quelques remarques sur la culture géographique de l'historien, pp. 37-52; Caroline CHEVALIER-ROYET, Entre tradition et innovation: Raban Maur, un érudit carolingien face à ses sources, pp. 53-70; Marie BARRAL-BARON, Érasme et les "Adages" ou l'art de collecter, commenter et diffuser la culture savante de l'Antiquité, pp. 71-83; Deuxième partie («Le travail et la démarche 
intellectuelle de l'érudit»): Blandine coLoT, Lactance, le «Cicéron chrétien»: transmission des textes et contextes, pp. 87-100; Françoise BRIQUEL CHATONNET, Le travail d'un érudit à travers la correspondance du patriarche de l'Église de l'Orient Timothée I ${ }^{e r}$ (780-823), pp. 101-115; Pierre AGERON, Dans le cabinet de travail du pasteur Samuel Bochart. L'érudit et ses sources arabes, pp. 117-143; Troisième partie («Les aspects matériels de la production érudite»): François BÉRENGER, Le fonctionnement du scriptorium de Charles I $I^{\text {er }} d$ 'Anjou, pp. 147-161; Valérie NEVEU, Les recueils de lieux communs au regard des sciences de l'information: un modèle pour la classification bibliographique et l'indexation matières? (XVI'-XVIII siècle), pp. 163-181; Véronique SARRAZIN, Éditer l'érudition, en France, aux XVII et XVIII siècles, pp. 183-200; Quatrième partie («La culture savante»): Clémence REVEST, Les «sympathisants» de l'humanisme: le cas des frères Giobbe, Lazarino et Giona Resta, pp. 203-215; Iolanda VENTURA, Médecine et encyclopédies entre Renaissance et époque moderne: l'exemple de Giorgio Valla et de Johann Heinrich Alsted, pp. 217-235; Thomas GUILLEMIN, Le directeur de conscience déguisé en érudit pédagogue: la vanité des sciences d'Isaac Papin, pp. 237-250; Jacques MAILLARD, La vie culturelle des élites en Anjou au XVIII ${ }^{e}$ siècle, pp. 251-266.

3 Si segnalano due articoli concernenti il Rinascimento francese. Il primo è dedicato a un'opera di portata europea, gli Adagia erasmiani: BARRAL-BARON ripercorre dapprima la storia editoriale del fortunatissimo repertorio paremiografico, per poi rilevare come il lavoro di selezione, traduzione e commento di proverbi greci e latini testimoni una concezione dell'eruditio al servizio della fides. Nell'ultima parte dello studio, l'A. ricollega il monumentale progetto della raccolta all'ottimistica fiducia dell'autore nell'avvento imminente di una nuova età dell'oro, una fiducia destinata ad essere frustrata negli anni Venti dalle tensioni conseguenti la Riforma. Il secondo contributo, di NEVEU, è invece dedicato alle raccolte di lieux communs quali modelli per l'elaborazione di principi di indicizzazione nell'epoca moderna. Basandosi su un corpus di cinquanta titoli, alcuni dei quali proposti nell'articolo come casi-studio (fra questi si segnalano i lavori di Gesner et di La Croix du Maine), l'A. distingue due tipologie di raccolte cui corrispondono due tipologie di indici distinti: da un lato, i volumi di carattere generale, solitamente di taglio morale o filosofico; dall'altro, i volumi di carattere pratico o professionale, dedicati a discipline quali teologia, diritto o medicina. Sarebbero le tecniche di indicizzazione adottate per questi ultimi, in particolare, ad aver contribuito allo sviluppo degli strumenti bibliografici e dei sistemi di classificazione dell'informazione moderni. 